\title{
Economic Analysis of the Pearl River Delta's "Labor Shortage"
}

\section{Xiao-ran, HEYan-ming, WU Cheng-cheng}

School of Management, Guangdong University of Technology, Guangzhou, China

\begin{abstract}
The shortage of workers in the Pearl River Delta is becoming increasingly severe. The enterprise can hardly employ enough workers. Based on the supply-demand model, this paper analyzes the phenomenon from the view of economic, and bases on the Lewis Model analyze the deep cause of this situation. This paper argues that the best way to solve this problem is to speed up the industry transition and upgrading, improve the post technical content, in order to radically reduce labor demand.
\end{abstract}

Keywords: Worker Shortage, Pearl River Delta, Supply-Demand Model, Lewis Model

\section{INTRODUCTION}

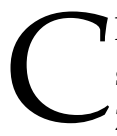
hina has been taken into account the state that can supply unlimited labor. However, from the year of 2004, this kind of view has been broken down again and again, and the shortage of labor has become increasingly serious. Employment difficulty refers to the phenomenon of the labor shortage. Data shows that the Pearl River Delta region has the most serious labor shortage problem. In 2006, Guangdong Province's labor gap reached 2,500,000; after the outbreak of the global economic crisis, labor shortages had been alleviated. Butin 2010, with the economic recovery, labor shortage it the Pearl River Delta again. And the labor gap added more than 2000000; in 2011, there are 1.36 positions corresponding to each job seekers in enterprises of Guangzhou. ${ }^{[1]}$ The survey from China Textile Association shows that, in 2011just before the Spring Festival, the number of labor shortage has reached over 2 million in Guangzhou, Dongguan, etc. ${ }^{[2]}$ In 2013 just after the Lantern Festival, there were hundreds of job fairs in Shenzhen, of which $70.27 \%$ enterprises need to increase the number of employees, and nearly $90 \%$ of the companies were willing to raise $5 \%-15 \%$ to attract applicants'. But even so, job seekers also did not increase, but decreased when compared to previous years and many job seekers said that they were still in the wait-and-see. [3] In 2014, this phenomenon has not yet been alleviated; a monthly salary of 4000 is still hard to recruit employees.

The reason why the phenomenon of labor shortage is that, for one thing, the demand for labor force has been increasing, and then the labor has more choices in the inland cities, for another, they feel they don't belong to the city they work in. However, the deep reasons for this phenomenon are not only those above. This paper is based on the model of supply and demand, combines the Lewis model, and uses the opportunity cost theory to analyze the deep-seated causes of this phenomenon. At last, we give some solutions to address this problem and put forward countermeasures and suggestions.

\section{LABOR'S SUPPLY AND DEMAND ANALYSIS OF THE Pearl River Delta Region}

Analysis of labor's supply and demand based on the Supply - Demand Model

The supply amount of labor is determined by many factors. we only selected quantitative factors: opportunity cost and income. The opportunity cost includes home farming income, the nearest employment income and other aspects. Supply function can be given in $Q=S(C, I)$. Among them, $Q$ refers to the labor supply, $S$ refers to the function relationship, $C$ refers to the opportunity cost, I mean the revenue level.

Which is worth noting is that, generally, the Supply Demand function uses price (or wage) as the vertical axis and the number as the abscissa axis. In this paper, in order to better analyze the cause of labor mobility, we use the opportunity cost as the vertical axis, the quantity of the labor force as the abscissa axis. Analysis shows that supply and opportunity cost changes reversely, and supply has a positive relationship with income level. 
When income level is fixed, the demand curve in Figure 1 can be obtained:

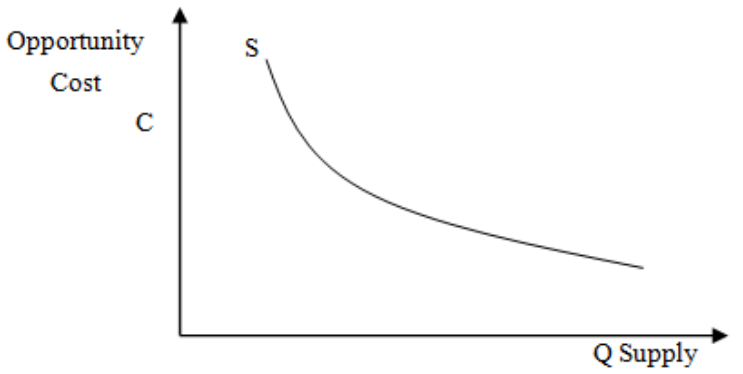

Figure 1 Labor supply curve when income is fixed

As we can see from the figure, the opportunity cost and the labor supply changes into the reverse relationship: when the opportunity cost increases, the labor supply cuts; while reducing opportunity costs, labor supply increased.

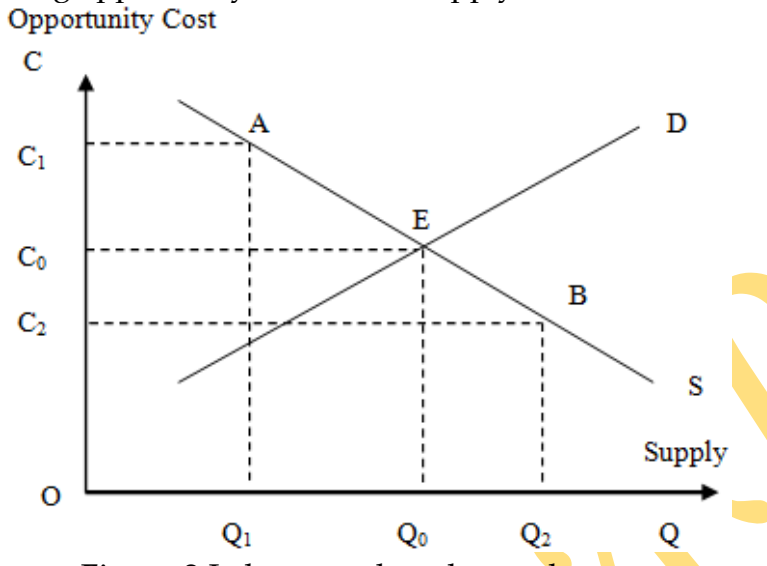

Figure 2 Labor supply - demand curve

In figure 2, DE is the demand curve, while AS refers to the supply curve. When the opportunity cost is at point A, workers' demand is $Q_{1}$. At this time the amount of supply is less than the demand, and the opportunity cost is a little high, so the farmers are reluctant to give up the high opportunity cost and go to other places to work. Because of the shortage of supply, the enterprise constantly raises the salary. Therefore, the opportunity cost decreases relatively. However, when farmers consider that the salary is higher than the opportunity cost, they will choose to work outside, which is consistently increasing the supply. As a result, the balance point moves from point A to point B, and supply amount moves from $\mathrm{Q}_{1}$ to $\mathrm{Q}_{2}$. At this time, the supply exceeds the demand, then the enterprise will reduce wages, which mean that the opportunity cost is relatively higher, and then the supply will decrease. As the result, point $\mathrm{B}$ will move to the left. At last, the balance point will be at point E. At point E, supply equals demand and Qois the best supply, while $\mathrm{C}_{0}$ is the opportunity cost when balancing. But the balance of supply and demand is only an ideal state. In reality, migrant workers would also consider the distance away from home, taking care of the family and so on, and are willing to give up the high wages of working outside and select farming at home or work nearby.

\section{Analysis of labor's supply and demand based on the Lewis Model}

Lewis (Lewis, 1954) pointed out that the economy in developing countries can be divided into the industrial sectors and the traditional sectors. In the industrial sector, there are a large number of machinery and equipment, and the producing progress is based on the modern ways, however, there is also a serious shortage of labor force; On the other hand, in traditional department, there is a severe capital shortage, but there are a huge number of surplus productivity. Industrial sector can employ the number of labors that they need under the fixed wage levels, and this process will continue until the surplus labor migration is finished [5]. At that moment, we can consider that the supply of labor achieves the balance.

Lewis believes that economic development can be divided into three stages: The first stage emerges when the marginal productivity of agriculture is zero. Under the premise of the industrial sector along with the continued expansion, it needs more and more surplus rural productivity. This is the industrial sector in a linear wage level absorbing rural surplus labor infinitely. [5]According to the theory of supply and demand, the enterprises' demands for labor is expanding, at this time the slope of enterprises demand curve is positive. The supply of labor is also very surplus, but the outflow of labor has no stimulation to the increase of labor productivity, so the opportunity cost of labor transfer does not change, that is to say, the labor supply curve shows the horizontal state. At the first stage, the figure 3 shows that $\mathrm{C}$ moves to $\mathrm{E}$ point, the demand is continuously reducing for the continuous supply.

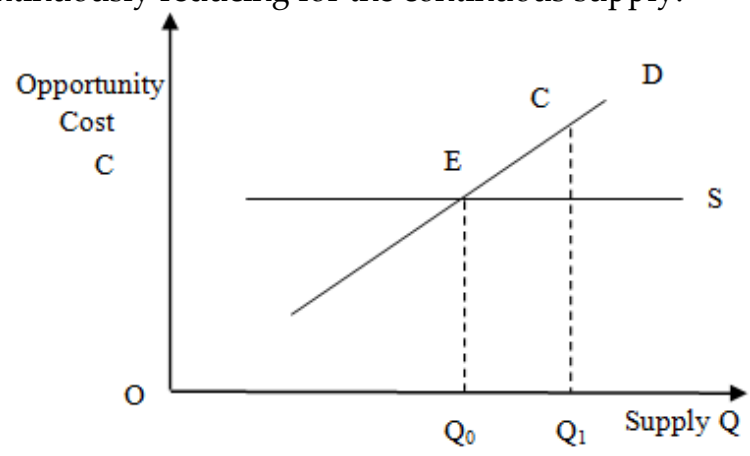

Figure 3 the first stage supply and demand analysis Before the year 2004 Unlimited supply of China's rural labor force, which isin the first stage of the Lewis model, under the existing level of wages, companies can hire any number of labor. At this point, agricultural income was low, also migrant workers' work opportunity cost was low. As the result, a large number of farmers moved 70 | $\mathrm{P}$ a g e 
into cities, in order to obtain a higher income. This formed a large scale. "The tide of migrant workers".

The second stage, the marginal productivity in agriculture is greater than zero, but less than the minimum average cost of living. Under the premise of rural surplus labor flowing out constantly, which leads to the labor productivity in agricultural sector gradually increases, and also increases farmers' income level, narrowing the income gap with industrial departments. Then the opportunity cost of labor mobility increases. At this point, if the industrial sector doesn't increase wages correspondingly, the agricultural labor force will choose to stay at home rather than going out to work. ${ }^{[5]}$ According to the model of supply and demand, at this stage, the development of enterprise scale is not considered. Therefore, assuming that, the enterprise demand remains unchanged, which means the labor demand curve is perpendicular to the horizontal axis. The slope of the labor supply curve is negative. In figure $4, F$ point moves to $G$, while the opportunity cost moves from $C_{1}$ to $C_{2}$. In the increasing process of opportunity cost, if the enterprise does not improve the wages correspondingly, they cannot hire enough people, as is shown on figure 5.

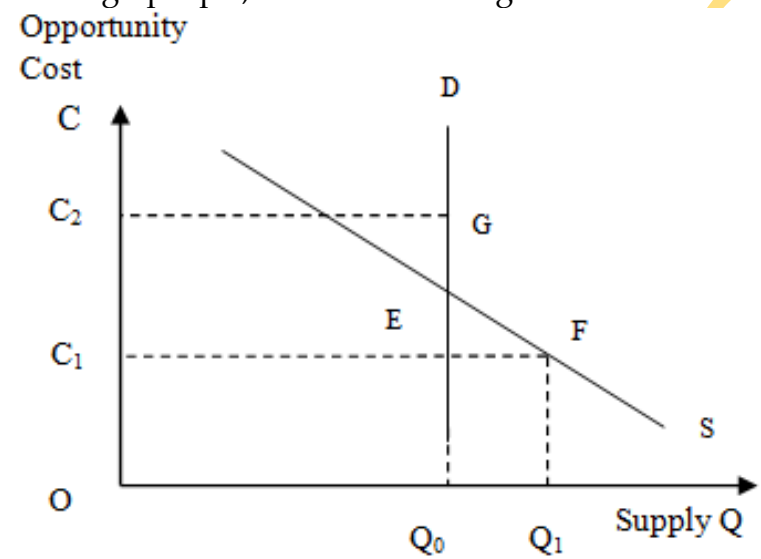

Figure 4 stage 2 supply and demand analyses

After the year 2004, the agricultural productivity was increasing gradually, narrowing the gap between working outside and staying at home. As the result, the migrant workers choose to stay township, so mobility of labor flow outward also weakens. However, our country's agricultural surplus labor force is not completely absorbed by the industrial sector; there is a large room to grow. As long as the enterprise can realize the change of external environment, and change their employment conditions and standards accordingly, labor mobility will not stop. In the first two stages, economic growth shows the absorption of surplus labor, rather than the general increase of actual income.

In the third stage, under the premise of the marginal productivity in agriculture is greater than the minimum average cost of living. The farmers' work opportunity cost is higher and higher. So the agricultural surplus labor is in disappearing. Instead, the workforce condition becomes short and tense. As is shown in figure 4, the opportunity cost is at $C_{1}$ level, at this time, the supply of labor is $Q_{2}$, the demand is $Q_{1}$, so the labor gaps is $Q_{1}-Q_{2}$. Opportunity

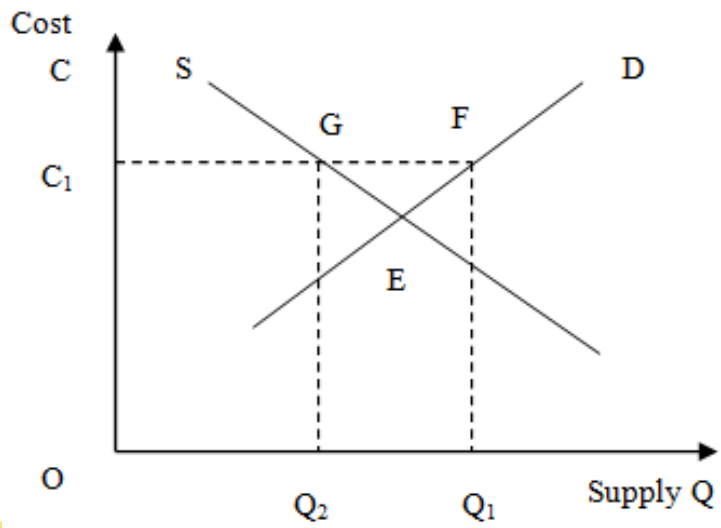

Figure 5 stage 3 supply and demand analyses

Then, in order to recruit enough workers, the enterprise will continue to increase the level of wage. But under the existing technology, the salary growth quota is limited. Also, Enterprises will improve technology, increase production capacity and reduce the cost, so that they can further raise wages to attract labor. When enough labor transfer to industrial department, traditional department begins to collapse. At that time, the main task of industrialization has been completed, and the developing countries have developed into developed countries. The completion of industrialization marks the dual economic structure turn to the unitary economic structure.

From the first stage to the second stage, the supply of labor changes from unlimited state to short state. This period, we regard it as the arrival of "the first Lewis turning point". When the marginal product of the traditional department and industrial sector equals, it also means, it turns to the third stage of the unitary economic structure, we call it the "the second Lewis turning point" at this time. ${ }^{[5]}$

So we can determine that, now in China, we are just pass "the first Lewis turning point", get into "the second Lewis turning point". The supply of labor is no longer unlimited, and the workforce begins to appear a large gap, businesses are starting to transform. According to statistics, only in the Pearl River delta, Processing and manufacturing enterprises' workers gap is as high as 2 million ${ }^{[6]}$. The companies that cannot hire enough workers in the "shortage of migrant workers" are the companies in the big demand for migrant workers, low wages, strong working strength, poor working conditions of manufacturing industry and service industry ${ }^{[7]}$. Manufacturing and construction industry 71 | P a g e 
are still the main areas that short of employment. The proportion of service industry is increasing, but the new generations of migrant workers are still largely focused on manufacturing industry. ${ }^{[8]} \mathrm{As}$ far as we can see, these enterprises are labor-intensive enterprises, and the technology content is low. At the same time, the "labor shortage" is more serious for small and medium-sized enterprises, because these enterprises has not yet developed the modern production, also the production value is limited, so companies are reluctant to raise wages to attract workers. Therefore, the likely consequence of improving wages is that the enterprises will not make ends meet. However, for large enterprises, the "labor shortage" is also not allowed to ignore, raise wages can't meet the needs of migrant workers and they can't find enough workers, so they still need to improve the modernization of enterprises, replacing workers with machines, so that can further reduce production costs. In recent years, China has become one of the countries that the number of industrial robots is in the fastest growth. Since 2004, domestic robot market average annual growth rate becomes $40 \%$ or more. In the year 2011, the growth rate of industrial robot market in China is as high as $51 \%$, ranking the world's leading place. The absolute increment 2.3 thousand is second only to Japan and South Korea, ranking in the third place. ${ }^{[9}$ Robots, to a certain extent, reduce the stress of employment difficult, but still can't fundamentally solve this problem. Because various problems such as profit, cost, etc., small and medium-sized enterprise cannot afford robot production line still need a lot of labor.

\section{Conclusion AND Discussion}

Relative to the years of worker tide, the emergence of the employment difficult is caused by many reasons: Economic recovers steadily, so the labor demand is growing; The change of China's regional industrial structure gives migrant workers more choices; Also, the concept of migrant workers has changed; Working environment is not ideal, and labor rights are violated frequently; The pearl river delta region's cost of living is very high, while the level of wages is quite low, etc. ${ }^{[5]}$

According to the theory of supply and demand, in the case of demanding exceeds supply, there are two ways to achieve a balance between supply and demand. One way is to increase the supply, and the second way is to reduce demand. Based on the above analysis, the way to increase supply is not feasible, so the only way is to reduce demand. The change of supply is controlled by wages, opportunity cost and so on, and the improvement of wages has been the maximum which businesses can reach. The factors of the opportunity cost are beyond the control of the enterprise. So the only way to solve the labor difficulty fundamentally is that the enterprises take active measures to reduce labor demand. I believe that the fundamental measure for PRD enterprises to change the status is to reduce the labor demand by accelerating technological progress, upgrading and transferring industrial, and eliminating backward production capacity. Only when the labor-intensive enterprises are turned into technology-intensive enterprises or non-labor-intensive enterprises, can the labor shortage problem be solved fundamentally. According to Professor Zhang Yonghong from Department of Sociology in Sun YatSen University, the labor shortage will certainly accelerate the process of China's mechanization. According to "the 12th five national strategic emerging industry development plan" issued by the State Council in July 2012, the development and the industrialization of automatic control systems, industrial robotics, and other key components and devices industrialization of automatic control systems, industrial robotics, and other key components and devices should be promoted vigorously in intelligent manufacturing equipment industry. In 2015, the domestic market share of the intelligent measurement and control devices and components with independent intellectual property rights should reach $30 \%$, which can master core technologies of intelligent manufacturing systems

Meanwhile, possible measures also include reforming household registration migration system to solve the migrant workers' Registered permanent residence and their children's education issues, improving the employment environment, raising wages, providing space for the development of migrant workers with people-oriented, providing technical training and business cultural training for workers to enhance the loyalty of migrant workers and observing law signing employment contract to protect the fundamental interests of migrant workers, and to deal with labor relations properly.

\section{REFERENCES}

[1] Guo Wei, Dong Liu. The Causes of Current Labor Shortage [J]. The Journal of Shanghai Administration Institute. 2011(3):90-98.

[2] Yuanshui Cao. The Difficulties of Employment for the Enterprises, HRO Using "PAYMENT" to Keep Staffs. http://www.ce.cn/cysc/newmain/pplm/zcr/201303/06/t2013030 6_21439120.shtml

[3] Weiji Wu. Problems and Solutions of the Difficulties of Employment for the Enterprises in PRD [J]. Technology Information. 2011(6):205-206.

[4] Qianming Sang. The shortage of Workers, Who shorts? http://politics.people.com.cn/n/2013/0223/c7073120577009.html

[5] Min Wang. An Empirical Analysis of Influencing Factors of the Current Labor Shortage in Cities- the Influence of Preferential Agricultural Policies on Labor shortage [D]. Master Thesis. Dongbei University of Finance, Liaoning, China.

[6] Fengtian Zheng, Zhuqing $\mathrm{Xu}$. The Citizen and Shortage of Workers. http://blog.huanqiu.com/76534/2011-03-21/2000345/

[7] Jie Zheng. The Shortage of Workers, Where and How? http://finance.jrj.com.cn/2010/03/2611377198507.shtm

[8] The Employment Status and Outlook of Chinese migrant workers[C]. China Human Resources Development Report (2011-2012). Social Sciences Academic Press, 2012:161-181.

[9] Robot "Posts" Reflects the Upgrading of Manufacturing Industry. http://news.hexun.com/2013-03-28/152584799.html

[10] The Fact-finding of "The Shortage of workers". http://www.infzm.com/content/55842

$$
--0--
$$

